Article

\title{
Investigating Surface Urban Heat Islands in South America Based on MODIS Data from 2003-2016
}

\author{
Xiaojun $\mathrm{Wu}^{1}{ }^{1}$, Guangxing Wang ${ }^{1, *}$, Rui Yao ${ }^{1,+}$, Lunche Wang ${ }^{1}{ }^{\oplus}$, Deqing $\mathrm{Yu}^{2}$ and Xuan Gui ${ }^{1}$ \\ 1 Hubei Key Laboratory of Critical Zone Evolution, School of Geography and Information Engineering, \\ China University of Geosciences, Wuhan 430074, China; jiangwx@cug.edu.cn (X.W.); \\ yaorui123@cug.edu.cn (R.Y.); wang@cug.edu.cn (L.W.); guixuan@cug.edu.cn (X.G.) \\ 2 Remote Sensing Centre of Hunan Province, Changsha 410007, China; nzg@cug.edu.cn \\ * Correspondence: wanggx@cug.edu.cn; Tel.: +86-155-2702-9001 \\ + These authors contributed equally to this work.
}

Received: 10 May 2019; Accepted: 20 May 2019; Published: 22 May 2019

check for updates

\begin{abstract}
Surface urban heat islands (SUHIs) have been investigated in many regions around the world, but little attention has been given with regard to SUHIs in South America. In this study, Moderate Resolution Imaging Spectroradiometer (MODIS) land surface temperature (LST) data was used to investigate the diurnal, seasonal, and interannual variations in the SUHI intensity (SUHII, the urban LST minus the rural LST) in 44 South American cities in different climate zones and types of rural land. To examine the effects of factors that may influence the SUHII, correlations between the SUHII and the enhanced vegetation index (EVI), urban area, population, altitude, and anthropogenic heat emissions were performed. The results showed that the SUHI effect was obvious in South America. The mean daytime SUHII was higher than the mean night-time SUHII in all areas except for the arid climate zone. In the daytime, the summer displayed a stronger SUHII in the warm temperate climate zone than the other seasons. The night-time SUHII showed less obvious seasonal variations. In addition, the surrounding land cover influenced the SUHII. During the day, the SUHII was therefore stronger in rural areas that were covered by forests than in other types of rural land. Interannually, most cities showed an insignificant temporal trend in the SUHII from 2003 to 2016. The daytime SUHII was significantly and negatively correlated with the $\Delta$ EVI (the urban EVI minus the rural EVI) across the 44 cities, but a poor relationship was observed at night. In addition, anthropogenic heat emissions were positively correlated with the night-time SUHII. Urban area, population, and altitude were weakly correlated with the SUHII, which suggested that these factors may not have a significant impact on the spatial variations in the SUHII in South America.
\end{abstract}

Keywords: surface urban heat island; MODIS; vegetation; South America

\section{Introduction}

Accompanying rapid urbanization, the proportion of the global urban population increased from $45 \%$ in 1995 , to $54 \%$ in 2015 , and it will reach up to $66 \%$ in 2045 [1]. A series of environmental problems caused by rapid urbanization have raised public concerns. One of these problems is the urban heat island (UHI) phenomenon, where the air temperature of an urban area is higher than that in nearby areas during the night [2]. UHI has negative effects on water and air quality [3], net primary productivity [4], biodiversity [5], human health [6-8], and climate [9-13]. Generally, UHIs consist of two types: air UHI as estimated by weather stations and surface UHI (SUHI) as monitored by remote sensing technology and aircrafts [14]. The air UHI effect is considered to be more closely related to human health, although both types of UHI are still highly related to health $[9,15,16]$. Therefore, it is of 
great importance to understand the driving mechanism and ecological effects of SUHI on regional and global scales.

Many early UHI studies were conducted with weather stations. However, in situ data was confined because of sparse distributions and spatial discontinuities. SUHI has been widely studied in recent decades by monitoring the land surface temperature (LST) with remote sensing technology and aircraft. The highest SUHI intensity (SUHII, the urban LST minus the rural LST) generally occurs during the daytime, while the UHI peaks at night $[17,18]$. The UHI is rather weak in the daytime, but it becomes more pronounced after sunset. Under some specific conditions, studies have found that some relevant factors (e.g., urban geometry, thermal admittance, and moisture) were important control factors for the UHI intensity [18-20]. Remote sensors such as the Landsat TM/ETM+/TIRS and Moderate Resolution Imaging Spectroradiometer (MODIS) play important roles in SUHI research [21]. Generally, Landsat TM/ETM+/TIRS data are more commonly used to analyze SUHI on a fine scale, because of the higher spatial resolution [22-25]. Meanwhile, many studies have been conducted at regional or global scales, using MODIS LST products, due to its broad spatial coverage and high temporal resolution [14,26-31]. Most studies on the topic have shown that SUHIs have obvious diurnal, seasonal, and spatial variabilities. For example, Pongracz et al. [26] found that the SUHII in nine cities of central Europe (i.e., Belgrade, Bucharest, Budapest, Milan, Munich, Sofia, Vienna, Warsaw, and Zagreb) exhibited high monthly variabilities, and that the most intense SUHIs occurred on summer days. Roth et al. [17] studied satellite-derived UHIs in Vancouver, Los Angeles, and Seattle, and the results showed that the difference between urban and rural surface temperatures in the daytime was larger than that in the night. According to Zhou et al. [14], the daytime SUHII in southeastern China was higher than other regions. Some studies have investigated temporal trends in the SUHII. For example, Yao et al. [32] investigated interannual variations in the SUHII in China's 31 major cities from 2001 to 2015; they showed that the SUHII was increasing, and that the SUHI area was expanding. Additionally, some studies analyzed the underlying influencing factors of the SUHII, such as urban area, vegetation coverage, meteorological conditions, and anthropogenic heat emissions [12,14,33-38]. For example, Peng et al. [34] reported that the SUHIIs in 419 global cities had significant and negative relationships with the vegetation during the daytime, while an insignificant correlation was observed during the night. These studies have contributed to understanding the specific causes of the SUHI effect.

However, little attention has been paid to SUHI studies in South America. To our knowledge, only a few areas of South America have been investigated [39,40]; for example, Peres et al. [40] studied the SUHI in Rio de Janeiro (Brazil) from 1984 to 2015, and the results showed that the area of the SUHI in 2000-2015 was greater than that in 1984-1999. However, these previous studies mainly focused on the analysis of SUHI in single cities, and they neglected to consider the influences of potential driving factors. Therefore, it is necessary to systematically study the associated factors and temporal variations in the SUHIs of South America.

This research is a comprehensive study of the SUHI phenomenon in South America, and it is aimed at (1) revealing the diurnal and seasonal variations in the SUHII across 44 South American cities in different climate zones and types of rural land, from 2003 to 2016; (2) studying the temporal trends in the SUHII in these 44 cities; and (3) examining the relationship between the SUHII and its associated influencing factors, including vegetation, urban area, population, altitude, and anthropogenic heat emissions.

\section{Data and Methods}

\subsection{Study Area}

The land area of South America is approximately $17.8 \times 10^{6} \mathrm{~km}^{2}$, which makes it the fourth largest continent in the world, accounting for approximately $12 \%$ of the world's total land area. According to updated Köppen-Geiger classifications [41], South America has various climate zones, the main zones being equatorial, arid, and warm temperate climate zones. In South America, areas with an 
annual average precipitation that is above $1000 \mathrm{~mm}$ account for approximately $70 \%$ of the total area, and the average temperature during the coldest winter month is above $0{ }^{\circ} \mathrm{C}$. In addition, most of the population is distributed to cities along the northwestern and eastern coasts. In 1980, the urban population of South America accounted for $68 \%$ of the total South American population, and this number is expected to reach $85 \%$ in 2020 [42]. In this study, we chose 44 South American cities (urban agglomerations) with a 2014 population that was larger than one million, as the study area (Figure 1). The local information of each city is shown in Table 1.

Table 1. The local information of each city, including the country, latitude, longitude, altitude, climate zone, and type of rural land. The climate zone divisions are based on the Köppen-Geiger classifications.

\begin{tabular}{|c|c|c|c|c|c|c|}
\hline City & Country & Latitude & Longitude & Altitude (m) & Climate Zone & Type of Rural Land \\
\hline Montevideo & Uruguay & -34.83 & -56.17 & 26.38 & Warm Temperate & Grassland \\
\hline Buenos Aires & Argentina & -34.61 & -58.40 & 21.04 & Warm Temperate & Cropland \\
\hline Santiago & Chile & -33.46 & -70.65 & 570.17 & Warm Temperate & Grassland \\
\hline Rosario & Argentina & -32.95 & -60.64 & 23.47 & Warm Temperate & Cropland \\
\hline Córdoba & Argentina & -31.41 & -64.18 & 451.06 & Warm Temperate & Cropland \\
\hline Pôrto Alegre & Brazil & -30.03 & -51.23 & 42.95 & Warm Temperate & Grassland \\
\hline Florianópolis & Brazil & -27.60 & -48.55 & 18.35 & Warm Temperate & Grassland \\
\hline Joinville & Brazil & -26.30 & -48.85 & 13.28 & Warm Temperate & Forest \\
\hline Curitiba & Brazil & -25.43 & -49.27 & 915.05 & Warm Temperate & Forest \\
\hline Asunción & Paraguay & -25.30 & -57.64 & 110.81 & Warm Temperate & Grassland \\
\hline $\begin{array}{l}\text { Baixada } \\
\text { Santista }\end{array}$ & Brazil & -23.96 & -46.33 & 13.69 & Warm Temperate & Forest \\
\hline São Paulo & Brazil & -23.55 & -46.64 & 770.25 & Warm Temperate & Forest \\
\hline Campinas & Brazil & -22.91 & -47.07 & 608.43 & Warm Temperate & Cropland \\
\hline $\begin{array}{l}\text { Rio de } \\
\text { Janeiro }\end{array}$ & Brazil & -22.90 & -43.21 & 34.79 & Equatorial & Grassland \\
\hline $\begin{array}{l}\text { Grande } \\
\text { Vitória }\end{array}$ & Brazil & -20.31 & -40.31 & 20.19 & Equatorial & Grassland \\
\hline $\begin{array}{c}\text { Belo } \\
\text { Horizonte }\end{array}$ & Brazil & -19.92 & -43.94 & 870.04 & Equatorial & Grassland \\
\hline Santa Cruz & Bolivia & -17.80 & -63.17 & 411.61 & Equatorial & Grassland \\
\hline Cochabamba & Bolivia & -17.39 & -66.16 & 2628.62 & Warm Temperate & Grassland \\
\hline Goiânia & Brazil & -16.68 & -49.25 & 782.09 & Equatorial & Grassland \\
\hline La Paz & Bolivia & -16.50 & -68.15 & 3862.25 & Warm Temperate & Grassland \\
\hline Brasília & Brazil & -15.78 & -47.93 & 1116.89 & Equatorial & Grassland \\
\hline Salvador & Brazil & -12.97 & -38.51 & 38.42 & Equatorial & Cropland \\
\hline Lima & Peru & -12.04 & -77.03 & 381.30 & Arid & Bare Soil \\
\hline Maceió & Brazil & -9.67 & -35.74 & 51.37 & Equatorial & Cropland \\
\hline Recife & Brazil & -8.05 & -34.88 & 25.47 & Equatorial & Cropland \\
\hline João Pessoa & Brazil & -7.12 & -34.86 & 41.23 & Equatorial & Cropland \\
\hline Natal & Brazil & -5.80 & -35.21 & 49.52 & Equatorial & Grassland \\
\hline Fortaleza & Brazil & -3.74 & -38.54 & 19.83 & Equatorial & Grassland \\
\hline Manaus & Brazil & -3.10 & -60.03 & 56.26 & Equatorial & Forest \\
\hline $\begin{array}{c}\text { Grande São } \\
\text { Luís }\end{array}$ & Brazil & -2.54 & -44.28 & 30.61 & Equatorial & Grassland \\
\hline Guayaquil & Ecuador & -2.17 & -79.90 & 12.91 & Equatorial & Grassland \\
\hline Belém & Brazil & -1.46 & -48.48 & 19.71 & Equatorial & Forest \\
\hline Quito & Ecuador & -0.23 & -78.52 & 2766.80 & Warm Temperate & Grassland \\
\hline Cali & Colombia & 3.44 & -76.52 & 989.71 & Equatorial & Cropland \\
\hline Bogotá & Colombia & 4.61 & -74.08 & 2591.86 & Warm Temperate & Grassland \\
\hline Medellín & Colombia & 6.25 & -75.56 & 1602.91 & Equatorial & Forest \\
\hline Bucaramanga & Colombia & 7.13 & -73.12 & 857.72 & Equatorial & Forest \\
\hline Barquisimeto & Venezuela & 10.07 & -69.32 & 600.40 & Equatorial & Grassland \\
\hline Valencia & Venezuela & 10.16 & -68.01 & 473.51 & Equatorial & Grassland \\
\hline Maracay & Venezuela & 10.25 & -67.60 & 456.26 & Equatorial & Grassland \\
\hline Cartagena & Colombia & 10.40 & -75.51 & 10.98 & Equatorial & Grassland \\
\hline Caracas & Venezuela & 10.49 & -66.88 & 965.61 & Equatorial & Forest \\
\hline Maracaibo & Venezuela & 10.63 & -71.64 & 23.98 & Equatorial & Grassland \\
\hline Barranquilla & Colombia & 10.96 & -74.80 & 35.72 & Equatorial & Grassland \\
\hline
\end{tabular}




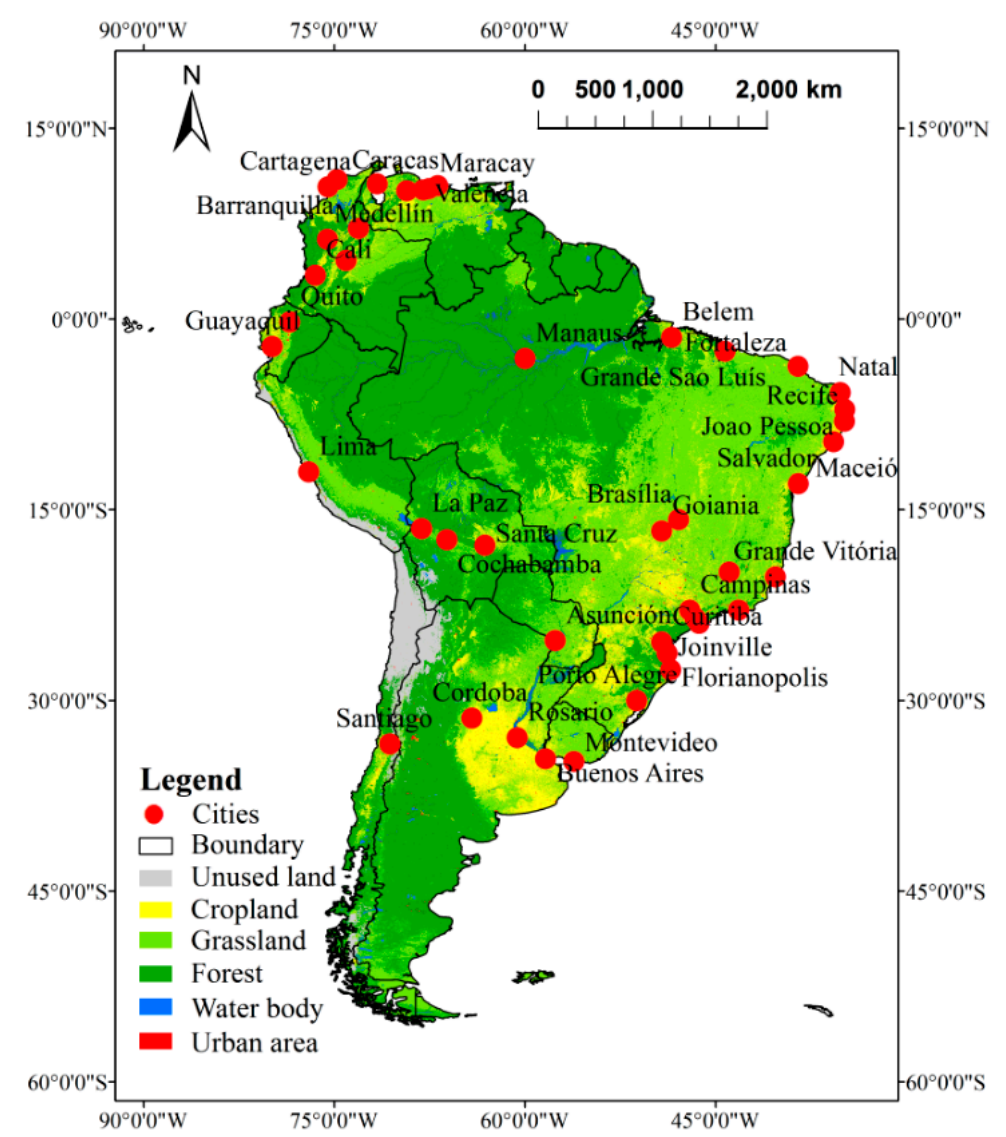

Figure 1. The spatial distribution of the 44 South American cities.

\subsection{Data}

MODIS LST data makes it feasible for diurnal and seasonal variations in the SUHI to be studied, because of the high temporal resolution of the data. Due to the wide coverage, it is an ideal data source for studying the SUHI effect at large or global scales. In this study, MYD11A2 data (8-day composite, $1000 \mathrm{~m}$ spatial resolution) was used to obtain the LST in South America from 2003 to 2016. According to Wan [43] and Pablos et al. [44], the absolute deviation of MODIS LST is less than $1 \mathrm{~K}$ in most cases. MOD13A3 data (monthly composite, $1000 \mathrm{~m}$ spatial resolution) and MODIS global land cover type data (MCD12Q1, $500 \mathrm{~m}$ spatial resolution) were used to extract vegetation greenness information from 2003 to 2016, and land cover information from 2013, respectively. Some studies have shown that the enhanced vegetation index (EVI) is more appropriate than the normalized difference vegetation index (NDVI) for monitoring vegetation variations in urban areas $[45,46]$.

The digital elevation model (DEM) data derived from ASTER GDEM (Version 1, 30 m spatial resolution), which was provided by Geospatial Data Cloud site, Computer Network Information Center, Chinese Academy of Sciences (http://www.gscloud.cn), was used to obtain altitude data for each city, and to eliminate the impacts of elevation on the SUHI. The urban population of each city in 2014 was provided by the United Nations (https://population.un.org/wup/). In this study, night light (NL) data was used as a proxy for anthropogenic heat emissions [14,34,47]. The composite VIIRS NL data from 2015 was obtained from the Earth Observation Group of the National Oceanic and Atmospheric Administration's National Geophysical Data Center (NOAA/NGDC, https://www.ngdc.noaa.gov/eog/index.html). Finally, the urban area of each city was calculated from the MCD12Q1 data.

\subsection{Methods}

To maintain consistency with the spatial resolution of the LST data, the MCD12Q1, DEM, and NL data were first resampled with nearest neighbor to $1000 \mathrm{~m}$. The SUHII was defined as the LST difference 
between the urban and rural areas. The urban area was extracted in the MCD12Q1 layer, according to the IGBP classification. If a nearby suburb had been used as a reference area, the SUHII may have been underestimated, due to the footprint of the SUHI being larger than the urban areas [48,49]. Therefore, a $20-25 \mathrm{~km}$ buffer was first generated around the urban area [32,46]. An area was excluded from the 20-25 km buffer if it met one of the following conditions: (a) it was classified as a water body or an urban area; (b) the elevation was outside the range of the average urban elevation $\pm 50 \mathrm{~m}[46,50,51]$, or (c) it was located within another city's $25 \mathrm{~km}$ buffer. The result was defined as being a rural area. A schematic diagram of the urban and rural areas (with Buenos Aires, Argentina, as an example) is shown in Figure 2. After the urban and rural areas were determined, the LST and EVI data were reprojected and mosaicked, using the MODIS Reprojection Tool (MRT). Both the daytime (13:30) and night-time (1:30) SUHII were computed for each city. Then, the seasonal and annual daytime and night-time SUHIIs were calculated for the years 2003-2016. In the Northern Hemisphere, spring, summer, autumn, and winter are defined as being the periods from March to May (MAM), June to August (JJA), September to November (SON), and December to February (DJF), respectively. In the Southern Hemisphere, spring, summer, autumn, and winter are defined as SON, DJF, MAM and JJA, respectively.

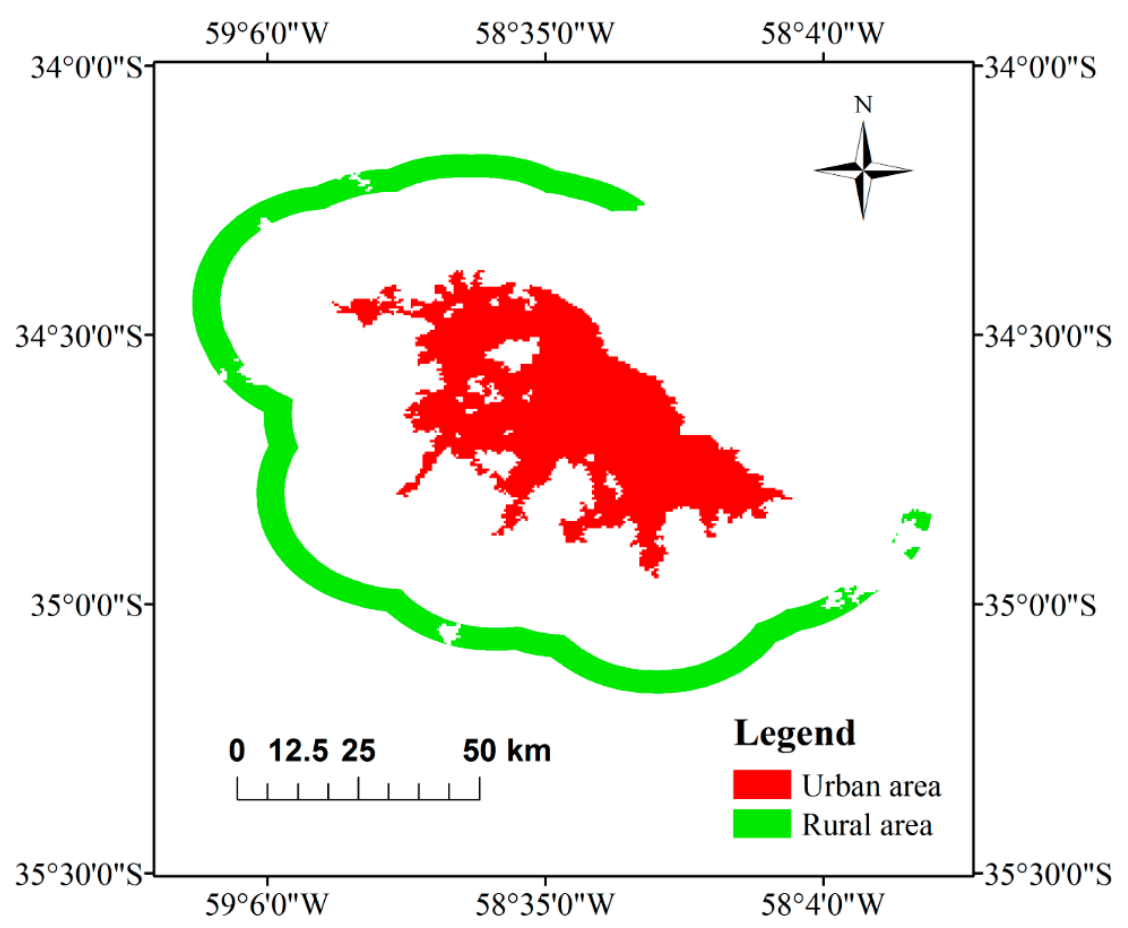

Figure 2. Schematic diagram of urban and rural areas, using Buenos Aires, Argentina as an example.

The NL difference $(\Delta N L)$ and the EVI difference $(\Delta E V I)$ were calculated between the urban and rural areas. The relationship between the SUHII and its associated influencing factors were analyzed by Pearson correlation analyses that were calculated using SPSS. Temporal trends in the SUHII in the 44 cities from 2003 to 2016 were conducted by linear regression analyses. The updated Köppen-Geiger classifications [41], which have been frequently used in climate classifications, were used to divide the 44 cities into equatorial, arid, and warm temperate climate zones. Based on updated Köppen-Geiger classification data, in this study, there were 26, 1, and 17 cities in the equatorial, arid, and warm temperate climate zones, respectively. In addition, to comprehensively understand the effects of differences in surrounding land cover types on the SUHI, rural areas were divided into four types according to the land cover classification: forest, cropland, grassland, and bare soil. If there were multiple land cover classifications in a rural area, the most common type which was chosen as the rural land type. In total, 9, 9, 25, and one cities were covered by forest, cropland, grassland, and bare 
soil, respectively. In this study, the diurnal, seasonal, and annual SUHII were calculated for different climate zones and different rural land types.

\section{Results}

\subsection{Diurnal and Seasonal Variations in the SUHII}

Figure 3 shows the annual and seasonal daytime SUHII. Positive daytime SUHII was observed in $40,39,39,40$, and 39 out of 44 cities for the annual, spring, summer, autumn, and winter time periods, respectively. This finding suggests that the SUHI effect is obvious in South America. The annual and seasonal night-time SUHII values are illustrated in Figure 4. The annual night-time SUHII values over most cities (36 of 44) were between $0{ }^{\circ} \mathrm{C}$ and $2{ }^{\circ} \mathrm{C}$, which showed that the night-time SUHII was more stable, with less obvious seasonal variations. This result was similar to that fromPeng et al. [34], who reported that the annual average night-time SUHII in $95 \%$ of cities worldwide was between $0{ }^{\circ} \mathrm{C}$ and $2{ }^{\circ} \mathrm{C}$.

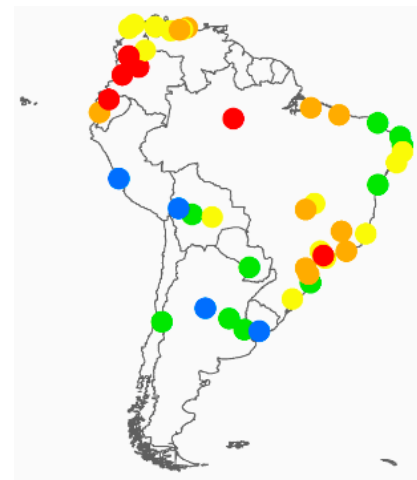

(a) Annual Day

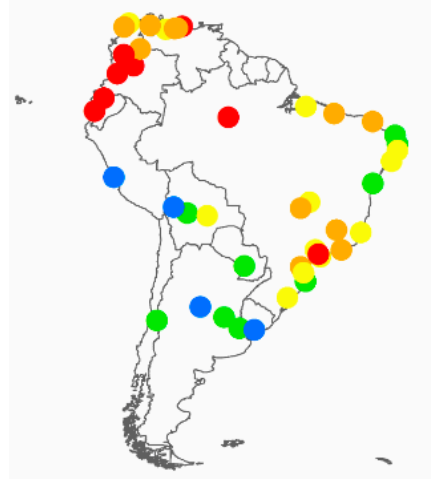

(d) Autumn Day

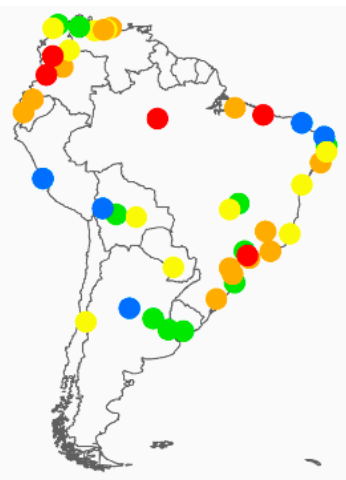

(b) Spring Day

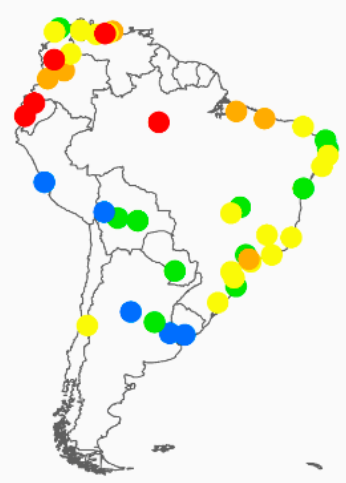

(e) Winter Day

Figure 3. The daytime surface urban heat island intensity (SUHII) for each city in South America.

Different climate zones may cause different patterns in the SUHI. Table 2 shows the mean diurnal and seasonal SUHIIs in different climate zones. Except for the arid climate zone, the daytime SUHII was higher than the night-time SUHII in each season. During the daytime, there was an obvious seasonal difference in the SUHII in the warm temperate and arid zones, but this phenomenon was not found in the equatorial climate zone. From 17 cities, the mean SUHII in the warm temperate climate zone was $2.77^{\circ} \mathrm{C}$ in the annual daytime, which was higher than that in the night-time $\left(1.34^{\circ} \mathrm{C}\right)$. In addition, the mean daytime SUHII values were $2.67{ }^{\circ} \mathrm{C}, 4.06{ }^{\circ} \mathrm{C}, 2.62{ }^{\circ} \mathrm{C}$, and $1.77^{\circ} \mathrm{C}$ in spring, summer, autumn, and winter, respectively (Table 2), which indicated that a higher SUHII occurred in summer than in the other seasons. Moreover, the surrounding land cover may have a large difference on the SUHII. The SUHII values, averaged over different types of rural land, are given in Table 3. A higher daytime SUHII was found in forest-covered rural areas, compared with the other area types. 
A "cold island" effect occurred in cities where the associated rural areas were covered by bare soil during the daytime. Similar to the above results, for all types of rural lands, the night-time SUHII was weaker than in daytime, with fewer observed seasonal variations.

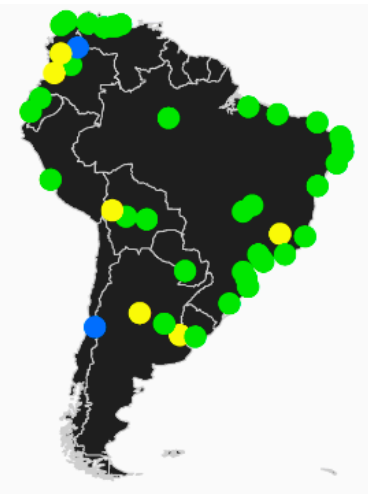

(a) Annual Night

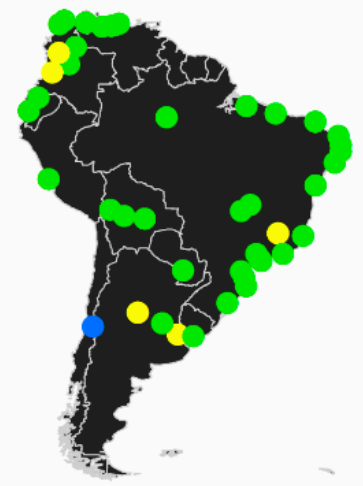

(d) Autumn Night

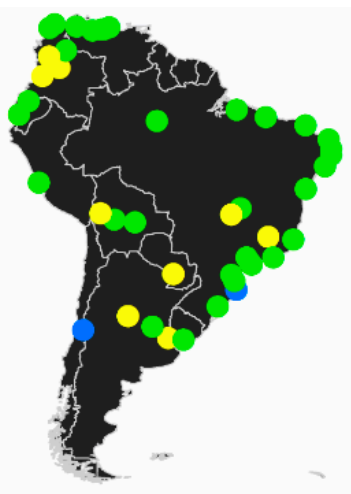

(b) Spring Night

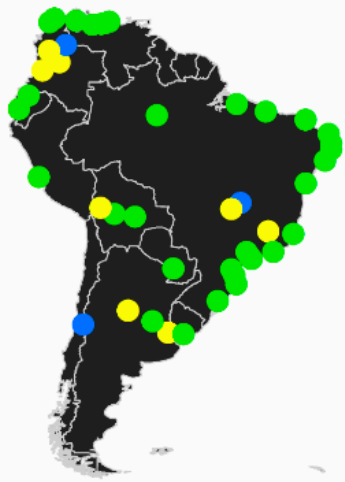

(e) Winter Night

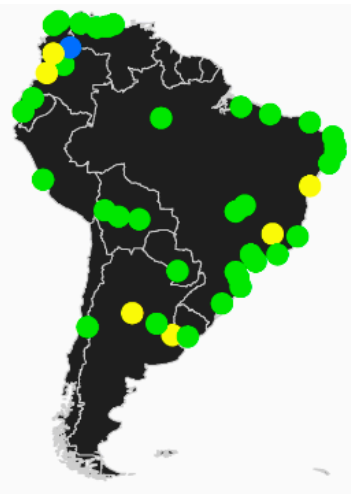

(c) Summer Night

Figure 4. The night-time SUHII values for each city in South America.

Table 2. The diurnal and seasonal surface urban heat island intensity (SUHII, ${ }^{\circ} \mathrm{C}$ ) in different climate zones of South America.

\begin{tabular}{ccccccc}
\hline \multirow{3}{*}{ Daytime } & Climate Zone & Spring & Summer & Autumn & Winter & Annual \\
\hline \multirow{5}{*}{ Night-time } & Equatorial & 3.45 & 3.93 & 4.16 & 3.61 & 3.80 \\
& Arid & -2.84 & -1.45 & -0.67 & -1.41 & -1.60 \\
& Warm temperate & 2.67 & 4.06 & 2.62 & 1.77 & 2.77 \\
& Equatorial & 1.32 & 1.22 & 1.15 & 1.18 & 1.22 \\
& Arid & 0.93 & 0.94 & 1.15 & 0.88 & 1.03 \\
& Warm temperate & 1.44 & 1.43 & 1.30 & 1.17 & 1.34 \\
\hline
\end{tabular}

Table 3. The diurnal and seasonal SUHII $\left({ }^{\circ} \mathrm{C}\right)$ in South America for different types of rural land.

\begin{tabular}{ccccccc}
\hline \multirow{3}{*}{ Daytime of Rural Land } & Spring & Summer & Autumn & Winter & Annual \\
\hline \multirow{5}{*}{ Tyght-time } & Forest & 5.58 & 6.05 & 5.32 & 4.92 & 5.47 \\
& Cropland & 1.96 & 2.60 & 2.09 & 1.59 & 2.06 \\
& Grassland & 2.59 & 3.72 & 3.49 & 2.55 & 3.09 \\
& Bare soil & -6.63 & -6.46 & -6.51 & -5.02 & -6.16 \\
& Forest & 1.29 & 1.11 & 1.11 & 1.02 & 1.13 \\
& Cropland & 1.85 & 1.85 & 1.60 & 1.54 & 1.71 \\
& Grassland & 1.20 & 1.17 & 1.11 & 1.10 & 1.15 \\
& Bare soil & 0.99 & 0.78 & 1.01 & 0.60 & 0.85 \\
\hline
\end{tabular}




\subsection{Temporal Trends in the SUHII in South America from 2003-2016}

Figures 5 and 6 show the temporal trends in the SUHII for the 44 South American cities monitored between 2003 and 2016. In the daytime, increasing trends in the SUHII were observed in most cities. In total, 14, 8, 12, six, and eight cities had significantly increasing trends in the SUHII for the annual, spring, summer, autumn, and winter time periods, respectively. The highest and significantly increasing annual, spring, summer, autumn, and winter rates were found in Santa Cruz (Bolivia, $0.12{ }^{\circ} \mathrm{C} /$ year, $p<0.05$ ), Florianópolis (Brazil, $0.12^{\circ} \mathrm{C} /$ year, $p<0.05$ ), Santa Cruz (Bolivia, $0.21^{\circ} \mathrm{C} /$ year, $p<0.05$ ), Santa Cruz (Bolivia, $0.11^{\circ} \mathrm{C} /$ year, $p<0.05$ ), and Maceió (Brazil, $0.12^{\circ} \mathrm{C} /$ year, $p<0.05$ ), respectively. Moreover, $4,2,5$, one, and three cities showed significantly decreasing annual, spring, summer, autumn, and winter trends in the SUHII, respectively. During the night-time, nearly half of the cities experienced increasing trends in the SUHII over the whole study period. The SUHII increased significantly in a few cities, as indicated by six, four, two, one, and eight cities for the annual, spring, summer, autumn, and winter periods, respectively. Furthermore, similarly increasing SUHII rates among these cities were found during the night-time. The highest and most significantly increasing annual, spring, summer, autumn, and winter rates were observed in Cali (Colombia, $0.05^{\circ} \mathrm{C} /$ year, $p<0.05$ ), Goiânia (Brazil, $0.05{ }^{\circ} \mathrm{C} /$ year, $p<0.05$ ), Campinas (Brazil, $0.03{ }^{\circ} \mathrm{C} /$ year, $p<0.05$ ), Santiago (Chile, $0.02{ }^{\circ} \mathrm{C} /$ year, $p<0.05$ ), and Córdoba (Argentina, $0.08^{\circ} \mathrm{C} /$ year, $p<0.05$ ), respectively. Three, one, three, one, and two cities showed significantly decreasing annual, spring, summer, autumn, and winter trends in the SUHII, respectively. The reason for the significantly decreasing trend is not clear. However, some factors were not considered in this study: an effect of randomness and a short study period (14 years) may have caused this phenomenon. For both day and night periods, the number of cities with significantly increasing trends in the SUHII was larger than those with significantly decreasing trends.

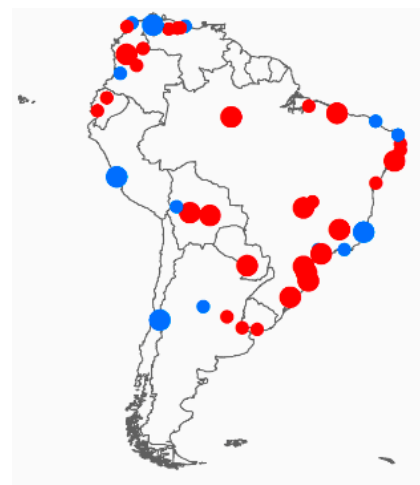

(a) Annual Day

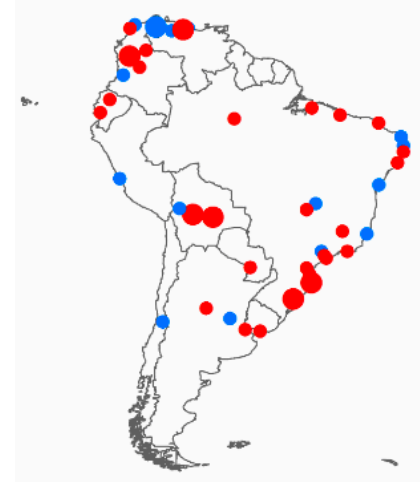

(d) Autumn Day

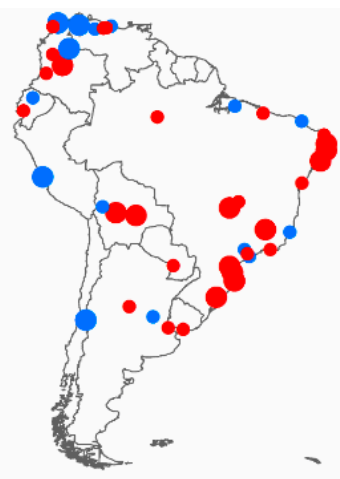

(b) Spring Day

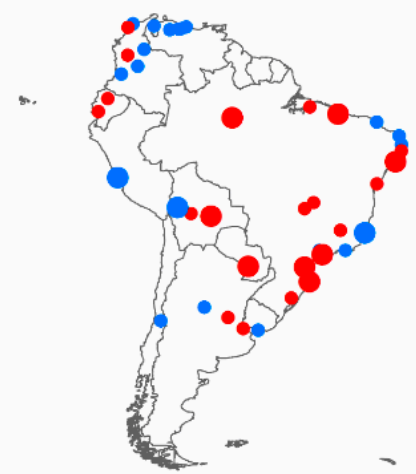

(e) Winter Day

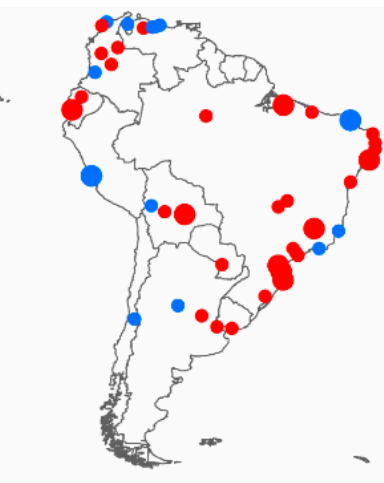

(c) Summer Day

Figure 5. Temporal trends in the daytime SUHIIs for each city from 2003 to 2016. 


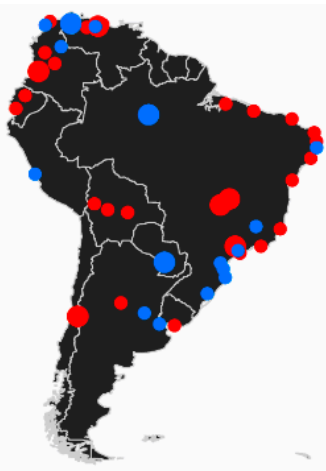

(a) Annual Night

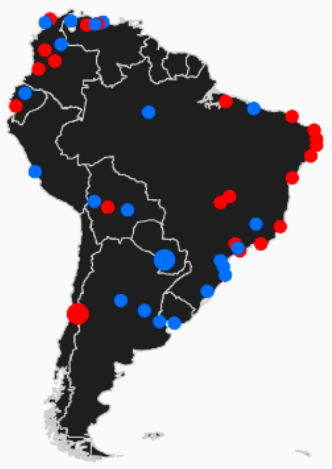

(d) Autumn Night

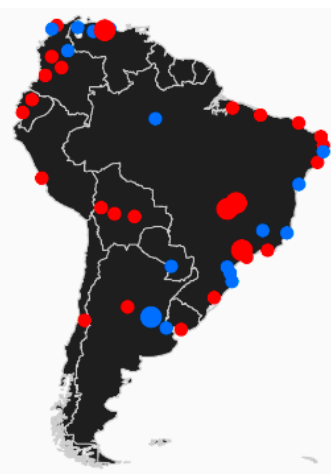

(b) Spring Night

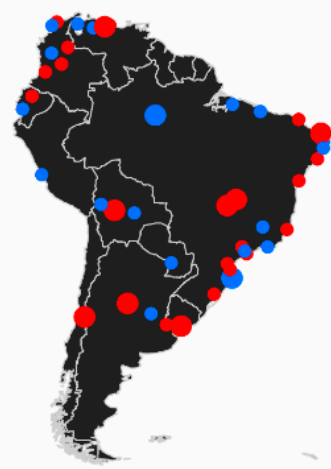

(e) Winter Night

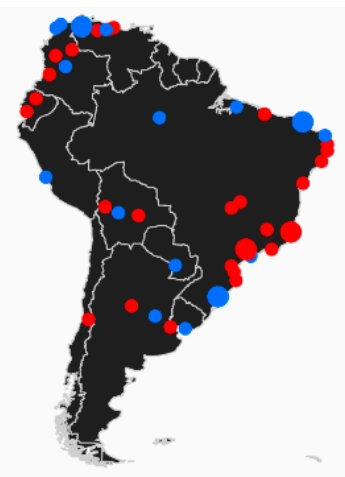

(c) Summer Night

\section{Legend}

Significant increase trend

- Insignificant increase trend

- Insignificant decrease trend

Significant decrease trend

Figure 6. Temporal trends in the night-time SUHIIs for each city from 2003 to 2016.

\subsection{Relationships between the SUHII and Its Potential Influencing Factors}

The relationships between the SUHII and its potential influencing factors were examined, which contributed to understanding the specific causes of the SUHI effect. The daytime SUHII was closely related to the $\triangle E V I$, but a poor correlation was observed at night. The daytime SUHII had a significant $(p<0.01)$ and negative relationship with the $\Delta$ EVI during each season (Table 4$)$, which suggests that during the day, as the $\triangle E V I$ decreases, the SUHII intensifies. The results of this study were similar to the results of Zhou et al. [14] and Peng et al. [34], who studied the relationship between the SUHII and vegetation, in summer and winter, in 32 Chinese cities and 419 global cities, respectively. Compared with the daytime, the correlations between the night-time SUHII and the $\Delta$ EVI were much weaker. These results were consistent with Zhou et al. [15], who reported an insignificant correlation between the night-time SUHII and the $\triangle E V I$. In addition, the night-time SUHII values were significantly and positively related to the night light difference $(\Delta \mathrm{NL})$ (a proxy of anthropogenic heat emissions). In contrast, the daytime SUHII values showed insignificant correlations with the $\Delta$ NL. For all seasons, and for both daytime and night-time periods, the SUHII values had poor correlations with the urban area (except during summer nights), the population, and the altitude, at each season. 
Table 4. Correlations between SUHII and the difference in the enhanced vegetation index $(\Delta \mathrm{EVI})$, urban area, population, altitude, and $\Delta \mathrm{NL}$ during the daytime and night-time, for each season.

\begin{tabular}{ccccccccc}
\hline \multirow{2}{*}{ Factors } & \multicolumn{4}{c}{ Daytime } & \multicolumn{4}{c}{ Night-time } \\
\cline { 2 - 9 } & Spring & Summer & Autumn & Winter & Spring & Summer & Autumn & Winter \\
\hline$\Delta$ EVI & $-0.81^{\mathrm{a}}$ & $-0.79^{\mathrm{a}}$ & $-0.78^{\mathrm{a}}$ & $-0.80^{\mathrm{a}}$ & -0.16 & -0.25 & -0.30 & -0.18 \\
Urban area & 0.04 & 0.14 & -0.04 & -0.10 & 0.20 & $0.36^{\mathrm{b}}$ & 0.25 & 0.13 \\
Population & 0.08 & 0.12 & -0.01 & -0.01 & 0.15 & 0.29 & 0.20 & 0.10 \\
Altitude & 0.17 & 0.24 & 0.20 & 0.13 & 0.02 & -0.08 & -0.02 & 0.01 \\
$\Delta$ NL & 0.21 & 0.31 & 0.22 & 0.12 & 0.31 & $0.63^{\mathrm{a}}$ & $0.46^{\mathrm{b}}$ & $0.51^{\mathrm{a}}$ \\
\hline \multicolumn{3}{c}{ a Significant at the 0.01 level; $^{\mathrm{b}}$ Significant at the 0.05 level. }
\end{tabular}

\section{Discussion}

\subsection{Diurnal and Seasonal Variations in the SUHII}

The same seasonal and diurnal trends of the SUHII values can be found in previous studies $[14,16,28]$. The phenomenon of a higher daytime SUHII compared with the night-time SUHII is explained by two factors. First, urban areas with artificial impervious surfaces and larger building densities resulting from urbanization will absorb more solar energy and radiation during the day [52], which can lead to higher LSTs in urban areas during the daytime. Second, the presence of vegetation affects the SUHI, due to evaporative cooling during the daytime. In the day, the largest diurnal differences in the SUHII values occurred in cities with rural areas that were covered by forest due to the cooler transpiration effect. However, an inverse relationship was found in arid regions. In arid regions, the LSTs in urban areas are generally lower than those in rural areas, which causes a negative annual daytime SUHII. Moreover, during the daytime, there were obvious seasonal variations in the SUHII, except in the equatorial climate zone. In the warm temperate climate zone, more vegetation coverage, more direct solar radiation, and a longer sunshine duration in summer may contribute to the obvious seasonal variations [34].

Peng et al. [34] investigated the SUHII values between 2003 and 2008 in 419 large cities worldwide, and the average 6-year SUHII in South America was weaker than our results (Table 5), except for summer nights $\left(2.4^{\circ} \mathrm{C}\right.$ for annual days; $1.1^{\circ} \mathrm{C}$ for annual nights; $3.0^{\circ} \mathrm{C}$ for summer days; $1.3^{\circ} \mathrm{C}$ for summer nights; $1.7^{\circ} \mathrm{C}$ for winter days; $0.9^{\circ} \mathrm{C}$ for winter nights). The reasons for this difference may be related to the temporal scale and the different methods for defining rural areas. Peng et al. [34] used nearby areas as referenced areas, which may have underestimated the SUHII, because the footprint of the SUHI extended beyond the urban areas $[49,50,53]$.

Table 5. The diurnal and seasonal SUHII values of 44 South American cities.

\begin{tabular}{cccccc}
\hline & Spring & Summer & Autumn & Winter & Annual Average \\
\hline Daytime & 2.86 & 3.74 & 3.34 & 2.67 & 3.15 \\
Night-time & 1.34 & 1.28 & 1.21 & 1.16 & 1.25 \\
\hline
\end{tabular}

The "cold island" effect occurred in Montevideo $\left(-0.11^{\circ} \mathrm{C}\right)$, La Paz $\left(-0.35^{\circ} \mathrm{C}\right)$, Córdoba $\left(-0.67^{\circ} \mathrm{C}\right)$, and Lima $\left(-6.19^{\circ} \mathrm{C}\right)$ in the annual daytime. This phenomenon may relate to low vegetation disturbances in rural areas, as indicated by the higher annual average $\triangle \mathrm{EVI}$ of these four cities mentioned above, compared to the other 40 cities (an average of -0.14 for the 40 cities): Lima (0.01), Córdoba $(-0.06)$, La Paz (-0.05), and Montevideo (-0.12). Almost no forested areas were found in these four cities. In Lima, the associated rural area was covered by desert with a high LST, which caused a significant cold island effect. Additionally, Lima is located near mountainous terrain, and it was possible that the slope of the mountains relative to the sun resulted in cold islands, due to the fixed monitoring times of the MODIS products. 
For all of the cities studied, the highest annual daytime SUHII was observed in Medellín (Colombia, $8.48^{\circ} \mathrm{C}$ ), followed by Manaus (Brazil, $6.86^{\circ} \mathrm{C}$ ), São Paulo (Brazil, $6.60^{\circ} \mathrm{C}$ ), Cali (Colombia, $6.25^{\circ} \mathrm{C}$ ), Quito (Ecuador, $6.11^{\circ} \mathrm{C}$ ), and Bogotá (Colombia, $6.02{ }^{\circ} \mathrm{C}$ ). The high SUHII values in these six cities may be caused by high vegetation coverage in the rural areas. According to Yao et al. [36], rural greening will increase the SUHII during the daytime. The mean proportion of forested areas in the six cities accounted for $52 \%$, while the proportion in other cities was only $20 \%$. The mean rural EVI and $\triangle \mathrm{EVI}$ in the six cities and other cities over different climate zones are given in Table 6 . The average absolute values of both the rural EVIs and $\triangle E V I s$ in the six cities were higher than in the other cities. Insignificant differences in the rural EVIs between the six cities and the equatorial cities were observed, but there was a smaller $\triangle E V I$ among the six cities, which helped to enlarge the difference in LST between the urban and rural areas. Vegetation plays a key role in attenuating the SUHI during the day, especially during the growing season [34]. This phenomenon can lead to higher SUHII values in these six cities. Additionally, the SUHII values in these six cities were high for each season (Figure 7), and this phenomenon was not observed in other cities. Although the geographical positions of these six cities were different, they are all located near the equator. The percentages of evergreen forest in the six cities were all above $95 \%$, which caused the mean rural EVIs and $\Delta E V I$ s to stabilize for each season. This may thus have caused fewer differences in seasonal variations for the SUHII.
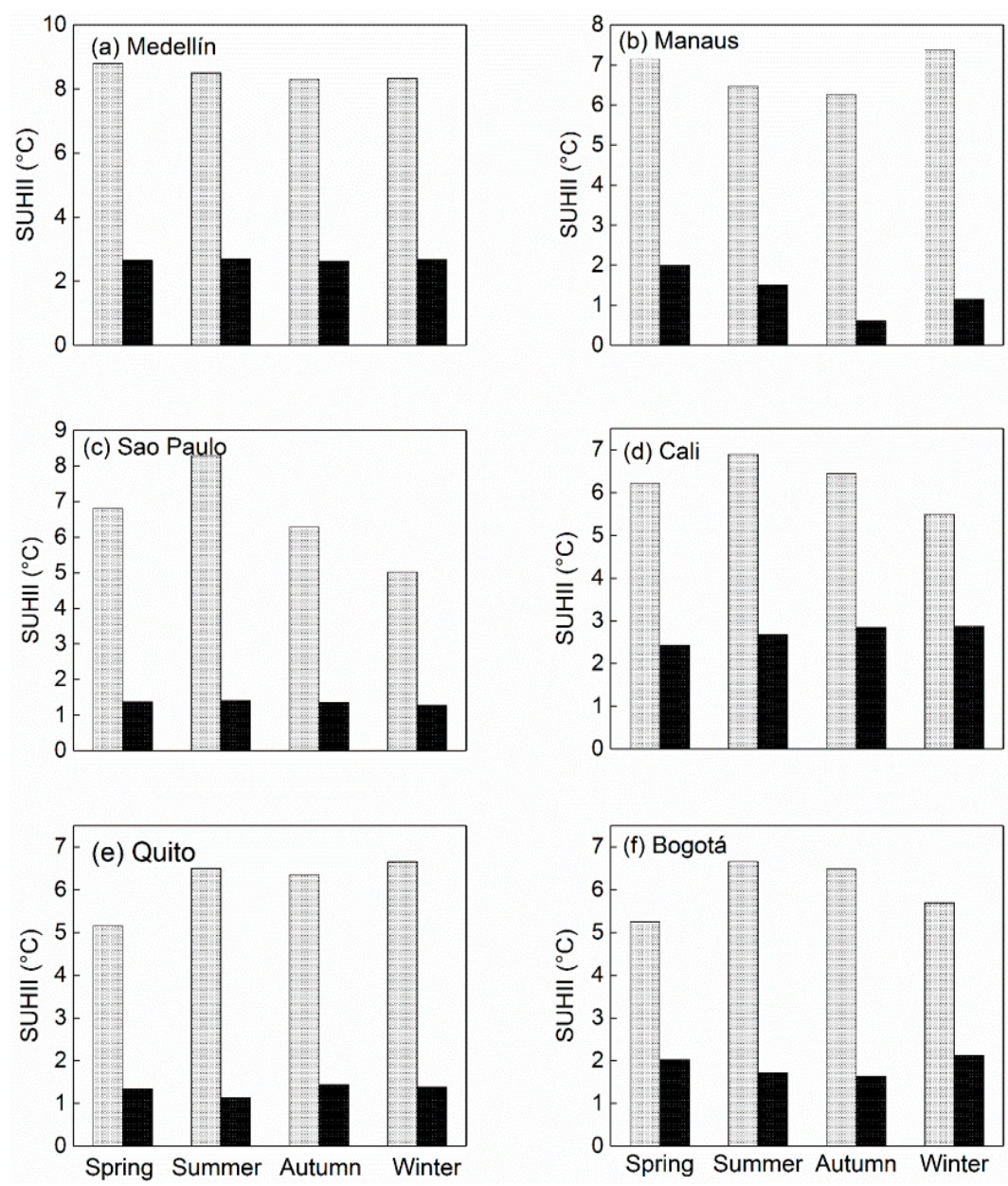

Figure 7. The average SUHII values from 2003-2016 for six cities: Medellín (Colombia), Manaus (Brazil), São Paulo (Brazil), Cali (Colombia), Bogotá (Colombia), and Quito (Ecuador). The gray and black columns represent the daytime and night-time SUHII, respectively. 
Table 6. The average rural EVI and $\triangle E V I$ for the six high-SUHII cities and the other 38 cities, in different climate zones. The six cities are Medellín (Colombia), Manaus (Brazil), São Paulo (Brazil), Cali (Colombia), Quito (Ecuador) and Bogotá (Colombia).

\begin{tabular}{cccccc}
\hline & Spring & Summer & Autumn & Winter & Annual \\
\hline Rural EVI & & & & & \\
Six cities & 0.43 & 0.46 & 0.44 & 0.43 & 0.44 \\
Equatorial cities & 0.36 & 0.43 & 0.45 & 0.39 & 0.41 \\
Warm temperate cities & 0.32 & 0.42 & 0.38 & 0.30 & 0.36 \\
Arid cities & 0.06 & 0.06 & 0.05 & 0.06 & 0.06 \\
$\quad \Delta$ EVI & & & & & \\
Six cities & -0.19 & -0.20 & -0.19 & -0.19 & -0.20 \\
Equatorial cities & -0.12 & -0.15 & -0.16 & -0.14 & -0.14 \\
Warm temperate cities & -0.09 & -0.13 & -0.12 & -0.10 & -0.11 \\
Arid cities & 0.01 & 0.01 & 0.02 & 0.00 & 0.01 \\
\hline
\end{tabular}

\subsection{The Effects of Each Factor on SUHII}

The relationship between the SUHII and vegetation was significant during the day, due to the evaporative cooling effect by vegetation [34]. The correlation for winter days was significant and negative between the $\triangle E V I$ and SUHII in this study, which was different to the results of other previous studies [14,34]. This phenomenon may be caused by a larger portion of evergreen vegetation being present in South America than in other regions, as some cities are located in the equatorial zone. Therefore, the vegetation of these cities is less affected by seasons, and so a decreasing $\Delta$ EVI can intensify the SUHII, even in winter. According to Zhou et al. [14] and Arnfield [9], the lack of vegetative transpiration during the night-time leads to an insignificant relationship between the $\triangle$ EVI and SUHII. It is inferred that vegetation plays an important role in mitigating the SUHI effect. Hu and Jia [54] found that the proportion of urban vegetation in Guangzhou, China decreased by 16\% from 1990-2007, which caused the LST to increase by $2.5^{\circ} \mathrm{C}$.

In this study, anthropogenic heat emissions were positively correlated with SUHII during the night, which was consistent with some previous studies [14,34]. However, an insignificant relationship was found during the day. According to Oke et al. [2,55], the energy balance of urban surfaces can be expressed as: net all-wave radiation + anthropogenic heat flux $=$ sensible heat flux + latent heat flux + net storage heat flux + net heat advection. Additionally, the net radiation is much larger than the anthropogenic heat flux during the day. Thus, anthropogenic heat emissions may be masked by net radiation, which would result in an insignificant relationship between the daytime SUHII and the anthropogenic heat emissions. However, during the night, anthropogenic heat emissions can contribute to the SUHI effect [56,57]. In this study, the link between the SUHII and urban area and population was insignificant. Urban area and population are surrogates for other urban planning variables, which could have indirect effects on the SUHI phenomenon. In this study, the effects of urban area and population on the SUHII may be masked by other factors, as the 44 cities are located within different climate zones, and they have different economic statuses and different rural environments. Thus, the effects of population and urban area on SUHII are weakened. Cities that were located in the equatorial climate zone and in rural areas covered by forest were chosen to test whether population and urban area were related to the SUHII. It was found that the annual daytime SUHII values of these cities exhibited significant and positive relationships with the population $\left(R^{2}=0.51, p<0.05\right)$ and urban area $\left(\mathrm{R}^{2}=0.47, p<0.05\right)$. Meanwhile, the altitude has little effect on the SUHII [58-60]. In this study, vegetation and anthropogenic heat emissions played a larger role in interpreting variations in the daytime and night-time SUHII values, respectively. 


\subsection{Uncertainties}

Some uncertainties exist in this study. First, the length of the study period (14 years) may have been too short a timeframe to properly study the temporal trends in the SUHII, because of the short time series of the MODIS LST products, which may have led to some biases in the analysis. Longer time-series data should be used in future studies on the interannual variation in the SUHII. Second, other factors that may influence SUHII, such as the soil moisture and the landscape configuration, were not conducted, due to problems with data availability. To explore these effects on the SUHII, factors that are related to the SUHII should be systematically analyzed in future works. Finally, it is not clear why some cities had significant decreasing trends. This result may be related to the short study period, or random effects or other factors that were not considered in this study.

\section{Conclusions}

In this study, the diurnal, seasonal, and interannual variations in the SUHIIs for 44 South American cities were investigated, using statistical data and remote sensing data from 2003 to 2016. Correlation analyses were conducted to reveal the relationships between the SUHII and $\Delta$ EVI, and urban area, population, altitude, and anthropogenic heat emissions.

The results showed that the daytime SUHII values were higher than the night-time SUHII, except in the arid climate zone. Seasonal variations were observed in the warm temperate and the arid climate zones. In the warm temperate climate zone, the highest SUHII was observed in summer $\left(4.06^{\circ} \mathrm{C}\right)$. At night, the SUHII values were between $0{ }^{\circ} \mathrm{C}$ and $2{ }^{\circ} \mathrm{C}$ in most cities, and there were no obvious seasonal variations. Additionally, the type of surrounding land cover affects the SUHII. A stronger daytime SUHII was observed in cities with forest-covered rural areas, compared with other types of rural land. Interannually, although the SUHII showed different temporal trends among the 44 cities, an insignificant temporal trend was found in most cities for the period from 2003-2016.

The SUHII and $\triangle E V I$ were significantly and negatively correlated during the daytime, but they were not significantly correlated during the night-time. In addition, anthropogenic heat emissions were positively correlated with the night-time SUHII. There was an insignificant correlation between the SUHII and the urban area, the population, and the altitude in this study.

Due to the significant SUHI effects observed in South America in recent years, variations in the urban thermal environment and the related ecological responses should be comprehensively analyzed. This study exhaustively investigated the diurnal, seasonal, and temporal trends, and the potential influencing factors for the SUHII in South America, which is an important reference for understanding the spatiotemporal variations in the SUHI effect, and the interactions between human activities and land-surface ecosystems. However, some uncertainties still remain, and other factors (e.g., landscape configurations and soil moisture) that are associated with the SUHI phenomenon should be thoroughly studied in future works.

Author Contributions: X.W. and L.W. designed the study; G.W., R.Y. and X.G. performed the experiments and analyzed the data; X.W. wrote the manuscript; L.W., D.Y., X.G., G.W., and R.Y. revised the manuscript.

Funding: This work was financially supported by the National Natural Science Foundation of China (No.41601044), the Special Fund for Basic Scientific Research of Central Colleges, China University of Geosciences, Wuhan (Nos.CUGCJ1704, CUGL170401).

Acknowledgments: We thank Zigeng Niu (China University of Geosciences) for constructive comments and suggestions.

Conflicts of Interest: The authors declare no conflict of interest.

\section{References}

1. United Nation. World Urbanization Prospects: The 2018 Revision; United Nation: San Francisco, CA, USA, 2017.

2. Oke, T.R. The Urban Energy Balance. Prog. Phys. Geogr. 1988, 12, 471-508. [CrossRef] 
3. Grimm, N.B.; Faeth, S.H.; Golubiewski, N.E.; Redman, C.L.; Wu, J.G.; Bai, X.M.; Briggs, J.M. Global change and the ecology of cities. Science 2008, 319, 756-760. [CrossRef]

4. Imhoff, M.L.; Bounoua, L.; DeFries, R.; Lawrence, W.T.; Stutzer, D.; Tucker, C.J.; Ricketts, T. The consequences of urban land transformation on net primary productivity in the United States. Remote Sens. Environ. 2004, 89, 434-443. [CrossRef]

5. Reid, W.V. Biodiversity hotspots. Trends Ecol. Evol. 1998, 13, 275-280. [CrossRef]

6. Gong, P.; Liang, S.; Carlton, E.J.; Jiang, Q.; Wu, J.; Wang, L.; Remais, J.V. Urbanisation and health in China. Lancet 2012, 379, 843-852. [CrossRef]

7. O'Loughlin, J.; Witmer, F.D.; Linke, A.M.; Laing, A.; Gettelman, A.; Dudhia, J. Climate variability and conflict risk in East Africa, 1990-2009. Proc. Natl. Acad. Sci. USA 2012, 109, 18344-18349. [CrossRef]

8. Patz, J.A.; Campbell-Lendrum, D.; Holloway, T.; Foley, J.A. Impact of regional climate change on human health. Nature 2005, 438, 310-317. [CrossRef]

9. Arnfield, A.J. Two decades of urban climate research: A review of turbulence, exchanges of energy and water, and the urban heat island. Int. J. Climatol. 2003, 23, 1-26. [CrossRef]

10. Dixon, P.G.; Mote, T.L. Patterns and causes of Atlanta's urban heat island-initiated precipitation. J. Appl. Meteorol. 2003, 42, 1273-1284. [CrossRef]

11. Jin, M.; Dickinson, R.E.; Zhang, D.A. The footprint of urban areas on global climate as characterized by MODIS. J. Clim. 2005, 18, 1551-1565. [CrossRef]

12. Hung, T.; Uchihama, D.; Ochi, S.; Yasuoka, Y. Assessment with satellite data of the urban heat island effects in Asian mega cities. Int. J. Appl. Earth Obs. Geoinf. 2006, 8, 34-48.

13. Jin, M.; Shepherd, J.M.; King, M.D. Urban aerosols and their variations with clouds and rainfall: A case 390 study for New York and Houston. J. Geophys. Res. Atmos. 2005. [CrossRef]

14. Zhou, D.C.; Zhao, S.Q.; Liu, S.G.; Zhang, L.X.; Zhu, C. Surface urban heat island in China's 32 major cities: Spatial patterns and drivers. Remote Sens. Environ. 2014, 152, 51-61. [CrossRef]

15. Zhou, D.C.; Zhang, L.X.; Li, D.; Huang, D.; Zhu, C. Climate-vegetation control on the diurnal and seasonal variations of surface urban heat islands in China. Environ. Res. Lett. 2016, 11, 074009. [CrossRef]

16. Clinton, N.; Gong, P. MODIS detected surface urban heat islands and sinks: Global locations and controls. Remote Sens. Environ. 2013, 134, 294-304. [CrossRef]

17. Roth, M.; Oke, T.R.; Emery, W.J. Satellite-derived urban heat islands from three coastal cities and the utilization of such data in urban climatology. Int. J. Remote Sens. 1989, 10, 1699-1720. [CrossRef]

18. Oke, T.R. Canyon geometry and the nocturnal urban heat island: Comparison of scale model and field observations. J. Climatol. 1981, 1, 237-254. [CrossRef]

19. Voogt, J.A.; Oke, T.R. Thermal remote sensing of urban climates. Remote Sens. Environ. 2003, 86, 370-384. [CrossRef]

20. Bonafoni, S.; Baldinelli, G.; Verducci, P.; Presciutti, A. Remote Sensing Techniques for Urban Heating Analysis: A Case Study of Sustainable Construction at District Level. Sustainability 2017, 9, 1308. [CrossRef]

21. Huang, Q.; Lu, Y. Urban heat island research from 1991 to 2015: A bibliometric analysis. Theor. Appl. Climatol. 2017, 131, 1055-1067. [CrossRef]

22. Tu, L.L.; Qin, Z.H.; Li, W.J.; Geng, J.; Yang, L.C.; Zhao, S.H.; Zhan, W.F.; Wang, F. Surface urban heat island effect and its relationship with urban expansion in Nanjing, China. J. Appl. Remote Sens. 2016, 10, 026037. [CrossRef]

23. Zhao, M.Y.; Cai, H.Y.; Qiao, Z.; Xu, X.L. Influence of urban expansion on the urban heat island effect in Shanghai. Int. J. Geogr. Inf. Sci. 2016, 30, 2421-2441. [CrossRef]

24. Parlow, E.; Vogt, R.; Feigenwinter, C. The urban heat island of Basel seen from different perspectives. J. Geogr. Soc. Berl. 2014, 145, 96-110.

25. Qiao, Z.; Tian, G.; Zhang, L.; Xu, X. Influences of Urban Expansion on Urban Heat Island in Beijing during 1989-2010. Adv. Meteorol. 2014, 2014, 11. [CrossRef]

26. Pongracz, R.; Bartholy, J.; Dezso, Z. Application of remotely sensed thermal information to urban climatology of Central European cities. Phys. Chem. Earth 2010, 35, 95-99. [CrossRef]

27. Shastri, H.; Barik, B.; Ghosh, S.; Venkataraman, C.; Sadavarte, P. Flip flop of Day-night and Summer-Winter Surface Urban Heat Island Intensity in India. Sci. Rep. 2017, 7, 40178. [CrossRef]

28. Wang, J.; Huang, B.; Fu, D.J.; Atkinson, P.M. Spatiotemporal Variation in Surface Urban Heat Island Intensity and Associated Determinants across Major Chinese Cities. Remote Sens. 2015, 7, 3670-3689. [CrossRef] 
29. Chakraborty, T.; Lee, X. A simplified urban-extent algorithm to characterize surface urban heat islands on a global scale and examine vegetation control on their spatiotemporal variability. Int. J. Appl. Earth Obs. Geoinf. 2019, 74, 269-280. [CrossRef]

30. Yang, Q.; Huang, X.; Tang, Q. The footprint of urban heat island effect in 302 Chinese cities: Temporal trends and associated factors. Sci. Total Environ. 2019, 655, 652-662. [CrossRef]

31. Weng, Q.H.; Fu, P.; Gao, F. Generating daily land surface temperature at Landsat resolution by fusing Landsat and MODIS data. Remote Sens. Environ. 2014, 145, 55-67. [CrossRef]

32. Yao, R.; Wang, L.C.; Huang, X.; Niu, Z.G.; Liu, F.F.; Wang, Q. Temporal trends of surface urban heat islands and associated determinants in major Chinese cities. Sci. Total Environ. 2017, 609, 742-754. [CrossRef]

33. Du, H.; Wang, D.; Wang, Y.; Zhao, X.; Qin, F.; Jiang, H.; Cai, Y. Influences of land cover types, meteorological conditions, anthropogenic heat and urban area on surface urban heat island in the Yangtze River Delta Urban Agglomeration. Sci. Total Environ. 2016, 571, 461-470. [CrossRef]

34. Peng, S.S.; Piao, S.L.; Ciais, P.; Friedlingstein, P.; Ottle, C.; Breon, F.M.; Nan, H.J.; Zhou, L.M.; Myneni, R.B. Surface Urban Heat Island Across 419 Global Big Cities. Environ. Sci. Technol. 2012, 46, 696-703. [CrossRef] [PubMed]

35. Weng, Q.; Lu, D.; Schubring, J. Estimation of land surface temperature-vegetation abundance relationship for urban heat island studies. Remote Sens. Environ. 2004, 89, 467-483. [CrossRef]

36. Yao, R.; Wang, L.; Huang, X.; Gong, W.; Xia, X. Greening in Rural Areas Increases the Surface Urban Heat Island Intensity. Geophys. Res. Lett. 2019, 46, 2204-2212. [CrossRef]

37. Wang, Y.; Berardi, U.; Akbari, H. Comparing the effects of urban heat island mitigation strategies for Toronto, Canada. Energy Build. 2016, 114, 2-19. [CrossRef]

38. Fan, H.; Sailor, D. Modeling the impacts of anthropogenic heating on the urban climate of Philadelphia: A comparison of implementations in two PBL schemes. Atmos. Environ. 2005, 39, 73-84. [CrossRef]

39. Palme, M.; Lobato, A.; Carrasco, C. Quantitative analysis of factors contributing to urban heat island effect in cities of latin-American Pacific coast. Procedia Eng. 2016, 169, 199-206. [CrossRef]

40. Peres, L.D.; de Lucena, A.J.; Rotunno, O.C.; Franca, J.R.D. The urban heat island in Rio de Janeiro, Brazil, in the last 30 years using remote sensing data. Int. J. Appl. Earth Obs. Geoinf. 2018, 64, 104-116. [CrossRef]

41. Rubel, F.; Kottek, M. Observed and projected climate shifts 1901-2100 depicted by world maps of the Köppen-Geiger climate classification. Meteorol. Z. 2010, 19, 135-141. [CrossRef]

42. United Nation Population Division. Available online: https://esa.un.org/unpd/wup/DataQuery/ (accessed on 3 July 2018).

43. Wan, Z.M. New refinements and validation of the MODIS Land-Surface Temperature/Emissivity products. Remote Sens. Environ. 2008, 112, 59-74. [CrossRef]

44. Pablos, M.; Martinez-Fernandez, J.; Piles, M.; Sanchez, N.; Vall-Ilossera, M.; Camps, A. Multi-Temporal Evaluation of Soil Moisture and Land Surface Temperature Dynamics Using in Situ and Satellite Observations. Remote Sens. 2016, 8, 587. [CrossRef]

45. Dallimer, M.; Tang, Z.; Bibby, P.R.; Brindley, P.; Gaston, K.J.; Davies, Z.G. Temporal changes in greenspace in a highly urbanized region. Biol. Lett. 2011, 7, 763-766. [CrossRef]

46. Zhou, D.; Zhao, S.; Zhang, L.; Liu, S. Remotely sensed assessment of urbanization effects on vegetation phenology in China's 32 major cities. Remote Sens. Environ. 2016, 176, 272-281. [CrossRef]

47. Amaral, S.; Câmara, G.; Monteiro, A.M.V.; Quintanilha, J.A.; Elvidge, C.D. Estimating population and energy consumption in Brazilian Amazonia using DMSP night-time satellite data. Comput. Environ. Urban Syst. 2005, 29, 179-195. [CrossRef]

48. Zhou, D.; Zhao, S.; Zhang, L.; Sun, G.; Liu, Y. The footprint of urban heat island effect in China. Sci. Rep. 2015, 5, 11160. [CrossRef]

49. Zhang, X.; Friedl, M.A.; Schaaf, C.B.; Strahler, A.H.; Schneider, A. The footprint of urban climates on vegetation phenology. Geophys. Res. Lett. 2004. [CrossRef]

50. Yao, R.; Wang, L.C.; Huang, X.; Niu, Y.; Chen, Y.S.; Niu, Z. The influence of different data and method on estimating the surface urban heat island intensity. Ecol. Indic. 2018, 89, 45-55. [CrossRef]

51. Yao, R.; Wang, L.; Huang, X.; Chen, J.; Li, J.; Niu, Z. Less sensitive of urban surface to climate variability than rural in Northern China. Sci. Total Environ. 2018, 628-629, 650-660. [CrossRef]

52. Kjelgren, R.; Montague, T. Urban tree transpiration over turf and asphalt surfaces. Atmos. Environ. 1998, 32, 35-41. [CrossRef] 
53. Han, G.; Xu, J. Land surface phenology and land surface temperature changes along an urban-rural gradient in Yangtze River Delta, China. Environ. Manag. 2013, 52, 234-249. [CrossRef]

54. Hu, Y.; Jia, G. Influence of land use change on urban heat island derived from multi-sensor data. Int. J. Climatol. 2009, 30, 1382-1395. [CrossRef]

55. Oke, T.R.; Cleugh, H.A.; Grimmond, C.S.B.; Schmid, H.P.; Roth, M. Evaluation of spatially-averaged fluxes of heat, mass and momentum in the urban boundary layer. Weather Clim. 1989, 9, 14-21.

56. Memon, R.A.; Leung, D.Y.C.; Liu, C.H. An investigation of urban heat island intensity (UHII) as an indicator of urban heating. Atmos. Res. 2009, 94, 491-500. [CrossRef]

57. Sailor, D.J. A review of methods for estimating anthropogenic heat and moisture emissions in the urban environment. Int. J. Climatol. 2011, 31, 189-199. [CrossRef]

58. Ye, X.; She, B.; Benya, S. Exploring Regionalization in the Network Urban Space. J. Geovisualization Spat. Anal. 2018, 2, 4. [CrossRef]

59. Rongali, G.; Keshari, A.K.; Gosain, A.K.; Khosa, R. Split-window algorithm for retrieval of land surface temperature using Landsat 8 thermal infrared data. J. Geovisualization Spat. Anal. 2018, 2, 14. [CrossRef]

60. Achour, H.; Toujani, A.; Rzigui, T.; Faïz, S. Forest cover in Tunisia before and after the 2011 Tunisian revolution: A spatial analysis approach. J. Geovisualization Spat. Anal. 2018, 2, 10. [CrossRef]

(C) 2019 by the authors. Licensee MDPI, Basel, Switzerland. This article is an open access article distributed under the terms and conditions of the Creative Commons Attribution (CC BY) license (http://creativecommons.org/licenses/by/4.0/). 